\title{
Development and formative evaluation of a community cookery book for use in deprived areas of Glasgow and East Dunbartonshire
}

\author{
E. Vargas ${ }^{1}$, J. Casey ${ }^{2}$, A. Parrett ${ }^{1}$ and A. L. Garcia ${ }^{1}$ \\ ${ }^{1}$ Human Nutrition, School of Medicine, College of Medical, Veterinary and Life Sciences, University of Glasgow, \\ Yorkhill Hospitals, Glasgow G3 8SJ, UK and ${ }^{2}$ Health Improvement Nutrition Network, Glasgow City Community Health \\ Partnership, Pavilion 1 Rowan Business Park, 5 Ardlaw Street, Glasgow G51 3RR
}

In the West of Scotland, unhealthy eating and deprivation are major factors strongly associated with poor health ${ }^{(1)}$. Policies are needed to reduce social inequalities that contribute to eating behaviour. The Scottish Government has stated that those on "a low income in particular require more support, education and skills development to allow people to break through barriers of food affordability and availability, and lack of food skills"(2). The development of health promotion materials to teach life skills and the promotion of healthier choices can all contribute to the uptake of a healthier diet ${ }^{(3)}$. Addressing a felt need, staff from the Health Improvement Nutrition Network (HINN) developed a cookery book as a tool to help both practitioners and the community promote healthy eating. To ensure the development of appropriate educational materials evaluation is necessary from the early stages of project planning, however this is often neglected due to lack of resources. Thus, the aim of this study was to contribute to the formative evaluation of the cookery book prior to its implementation.

In a cross-sectional study, the suitability of recipes and layout of the book was assessed using simple questionnaires in a sample of 108 participants and all deliverers $(n=8)$ of cooking skills courses in Glasgow City and East Dunbartonshire Community Health Partnerships (all members of the HINN). Qualitative analysis of the health message content was carried out using an evidence-based approach (searching relevant and supporting documents via Pubmed, NHS, FSA, Department of Health, and British Nutrition Foundation). To suit the target audience (low literacy), book readability was assessed using SMOG and Fry Graph formula and suitability of recipes content and organisation was done using a guide focused on written nutrition materials ${ }^{(4)}$. Nutritional composition and cost was calculated from a subsample of recipes $(n=18)$ using Windiets. Feedback was given to the network at different stages of the study to be considered for implementation.

Results from the questionnaires showed that $47 \%$ of participants favoured a notebook style of layout for the final design. Commonly eaten meals were soup (76\%), sandwiches $(63 \%)$, Indian takeaways $(28 \%)$, pasta dishes $(16 \%)$, chocolate $(14 \%)$, crisps $(21 \%)$, and soft drinks $(34 \%)$. Using suitable suggestions (e.g. soup, sandwiches, takeaways and pasta dishes), 70 recipes were adapted for the book alongside diet-orientated health messages which focused on standard recommendations (e.g. Eatwell plate and food labelling). Primary analysis showed high readability scores (Secondary 2 and 4 in Scottish education system). Lack of information about physical activity as a part of a healthy lifestyle was found in the health message analysis. Primary recipe analysis $(n=8)$ showed high levels of saturated fat and salt for $38 \%$ of the tested recipes. Following these findings recommendations were suggested and a second analysis of all aspects of the book was carried out. Improvements in readability scores to a lower level (Secondary 2 and Primary 7), and improvement in nutritional content of recipes $(n=8)$ was observed. Formative evaluation of the book provided an evidence-based health message and contributed to improve the readability for the target population. Further evaluation after implementation of the book is guaranteed.

1. Gray L, Leyland AH (2009) Public Health Nutr 12, 1351-1358.

2. Scottish Government (2005) Greater Glasgow NHS Oral Health Strategy. Glasgow.

3. Hughes G, Bennett KM \& Hetherington MM (2004) Appetite 43, 269-276.

4. Betterley C \& Dobson B (2000) Journal of Extension 38. http://www.joe.org/joe/2000august/tt3.php (Accessed May 2011). 